\title{
Short Communication \\ Longitudinal study on birthweight and the incidence of endometrial cancer
}

\author{
F Xue ${ }^{*, 1}$, LA Hilakivi-Clarke², GL Maxwell ${ }^{3}$, SE Hankinson ${ }^{4,5}$ and KB Michels ${ }^{1,4,5}$ \\ 'Obstetrics and Gynecology Epidemiology Center, Department of Obstetrics, Gynecology and Reproductive Biology, Brigham and Women's Hospital, and \\ Harvard Medical School, Boston, MA 021 I 5, USA; ²Georgetown University, Washington, DC, 20057 USA; ${ }^{3}$ US Military Cancer Institute, Walter Reed \\ Army Medical Center, Washington, DC, 20307 USA; ${ }^{4}$ Channing Laboratory, Department of Medicine, Brigham and Women's Hospital, and Harvard \\ Medical School, Boston, MA 02115, USA; ${ }^{5}$ Department of Epidemiology, Harvard School of Public Health, Boston, MA 021 I5, USA
}

From 1976 to 2004, we followed 7I 75I participants of the Nurses' Health Study and identified 676 invasive endometrial cancer cases. Birthweight, assessed in 1992, was not associated with the incidence of endometrial cancer. No effect modification by menopausal status was observed, but statistical power to detect an interaction was limited.

British Journal of Cancer (2008) 98, I288- I29I. doi:I0.1038/sj.bjc.6604304 www.bjcancer.com

Published online 18 March 2008

(c) 2008 Cancer Research UK

Keywords: endometrial cancer; birthweight; early life exposure; menopause; anthropometrics

Endometrial cancer is the commonest invasive gynecologic cancer in women in the United States, with nearly 40000 new cases diagnosed each year (American Cancer Society, 2007). Birthweight and intrauterine exposures have been related to the risk of breast cancer (Michels and Xue, 2006), childhood leukaemia (McLaughlin et al, 2006) and testicular cancer (Michos et al, 2007). However, data are limited regarding the potential influence of early life exposures on endometrial cancer risk. Potential mechanisms for an association between high birthweight and increased breast cancer risk include exposure to elevated maternal pregnancy oestrogen levels (Petridou et al, 1990; Ekbom et al, 1992), and insulin-like growth factor-I levels (Yang and Yu, 2000; Ostlund et al, 2002), both of which also affect the development of endometrial cancer (Ayabe et al, 1997; Adami et al, 2002). Prenatal nutrition may regulate body size later in life by altering the number of adipocytes (Sayer and Cooper, 2005), reprogram metabolism or influence leptin resistance (Phillips et al, 1999; Breier et al, 2001). As obesity is an established risk factor of endometrial cancer for premenopausal and postmenopausal women (Adami et al, 2002), birthweight as a marker of prenatal nutrition may plausibly influence its development.

Using data from 28 years of follow-up of 71751 women participating in the Nurses' Health Study (NHS), we examined the association between birthweight and incidence of endometrial cancer later in life.

\section{MATERIAL AND METHODS}

The NHS was established in 1976, when 121700 married registered nurses age 30-55 years replied to a baseline questionnaire and

*Correspondence: Dr F Xue; E-mail: n2fei@channing.harvard.edu Received II December 2007; revised 28 January 2008; accepted 15 February 2008; published online 18 March 2008 received questionnaires biennially by mail to update information on demographic, anthropometric, and life style factors, and on newly diagnosed disease. For the current analysis, we excluded women with missing birthweight data, prevalent cases of endometrial or other cancers, and women with hysterectomy at baseline. During follow-up, women were censored if they reported recently diagnosed in situ or invasive endometrial cancer, had a hysterectomy, died or were lost to follow-up.

In 1992, we asked participants to report their own birthweight with the following options: $<2.500,2500-<3182,3182-<3863$, $3863-<4545$, $\geqslant 4545$ g. On each biennial questionnaire, participants were asked whether they had been newly diagnosed with endometrial cancer during the previous 2 years. The National Death Index was also routinely searched for deaths among women who did not respond to the questionnaires. For endometrial cancers reported by women or their next of kin for those who had died, permission was requested to review the relevant medical records. Study physicians reviewed all medical records and pathological reports to confirm their diagnosis. Cases included in this study were invasive epithelial endometrial cancers with stage greater than IA in the FIGO staging system.

At baseline and during follow-up, we inquired about a variety of personal characteristics including reproductive and life style factors, many being risk factors for endometrial cancer. Information on age, age at menarche, age at first birth and height was obtained at baseline in 1976. Other early life exposures including premature birth $(2+$ weeks premature) and duration of having been breast-fed were assessed in 1992, and birth order was queried in 2004. Weight at age 18 was assessed in 1980. Somatotype at age 5 and 10 was assessed in 1988 by asking participants to choose from nine diagrams that best depicted their figure outline at each age. Maternal vital status and family history of endometrial cancer was asked in 1996. Other covariates were inquired and updated during follow-up. 
The association between birthweight and incidence of endometrial cancer was analysed using a Cox proportional hazards model. Three covariate-adjusted models were pursued. In the first model (model I), we adjusted only for family history of endometrial cancer and other early life exposures including birth order, duration of being breast-fed and premature birth, in addition to age. In the second (model II), we also included other established or potential risk factors for endometrial cancer. In the third (model III), we additionally adjusted for anthropometric factors, including somatotype at ages 5 and $10, \mathrm{BMI}$ at age 18 , and current BMI. Though covariate-adjusted models II and III have better goodness of fit due to additional adjustment for potential risk factors of endometrial cancer, these factors are subsequent to birthweight and could conceivably mediate the effect of birthweight on endometrial cancer risk. Therefore, adjusted model I would be the preferred model to estimate the overall effect of birthweight.

As birthweight was not assessed until 1992, we conducted a sensitivity analysis restricting follow-up to 1992-2004 and compared the results with the primary analysis using the entire follow-up. We also evaluated potential effect modification by menopausal status, anthropometric factors, and other early-life exposures.

\section{RESULTS}

During 1678702 person-years of follow-up among 71751 women, 676 cases of incident endometrial cancer were confirmed. Based on the eligible person-years, the follow-up rate for the entire cohort in

Table I Age-standardised distribution of demographic characteristics among 7| 75I women according to birthweight throughout follow-up 1976-2004 $(N=1678702$ person-years $)$

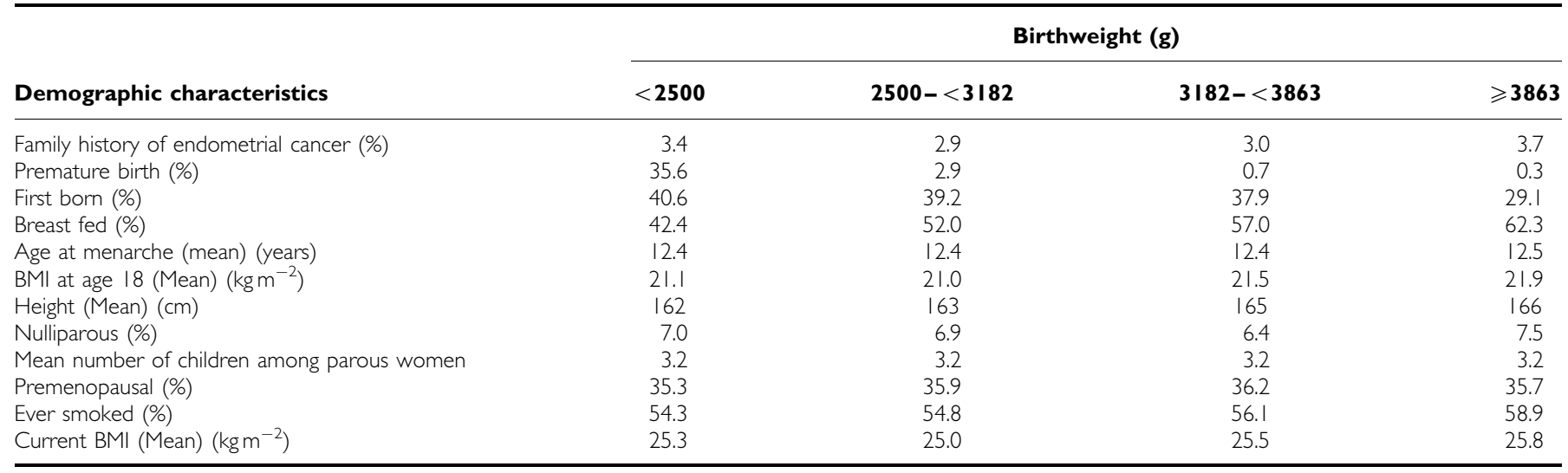

Table 2 Hazard ratio of endometrial cancer by birthweight among 7I 75I participants of the Nurses' Health Study during follow-up from 1976 -2004 and from 1992-2004

HR $(95 \% \mathrm{Cl})$

Birthweight (g) Person-years No. of cases Age-adjusted Covariate-adjusted I $\mathrm{I}^{\mathrm{a}}$ Covariate-adjusted II ${ }^{\mathrm{b}} \quad$ Covariate -adjusted III

\begin{tabular}{|c|c|c|c|c|c|c|}
\hline \multicolumn{7}{|c|}{ Follow-up 1976-2004 } \\
\hline$\geqslant 3863$ & 221515 & 84 & 1.0 & 1.0 & 1.0 & 1.0 \\
\hline $3182-<3863$ & 750698 & 307 & $1.14(0.89-1.46)$ & $1.15(0.90-1.47)$ & $1.14(0.89-1.47)$ & $1.18(0.92-1.51)$ \\
\hline $2500-<3182$ & 521674 & 208 & $1.10(0.85-1.42)$ & $1.10(0.84-1.42)$ & $1.08(0.83-1.41)$ & $1.15(0.88-1.50)$ \\
\hline$<2500$ & 184815 & 77 & $1.14(0.83-1.57)$ & $1.12(0.79-1.57)$ & $1.09(0.77-1.54)$ & $1.13(0.79-1.60)$ \\
\hline$P$ for trend & & & 0.52 & 0.63 & 0.74 & 0.48 \\
\hline \multicolumn{7}{|c|}{ Follow-up 1992-2004 } \\
\hline$\geqslant 3863$ & $7087 \mid$ & 54 & 1.0 & 1.0 & 1.0 & 1.0 \\
\hline $3182-<3863$ & 245954 & 207 & $1.16(0.85-1.56)$ & $1.16(0.86-1.58)$ & $1.16(0.86-1.58)$ & $1.19(0.87-1.61)$ \\
\hline $2500-<3182$ & 171030 & 123 & $0.99(0.72-1.37)$ & $1.00(0.72-1.38)$ & $0.98(0.71-1.36)$ & $1.03(0.74-1.43)$ \\
\hline$<2500$ & 60391 & 52 & $1.16(0.79-1.71)$ & $1.19(0.79-1.81)$ & $1.17(0.77-1.78)$ & $1.19(0.78-1.82)$ \\
\hline$P$ for trend & & & 0.91 & 0.87 & 0.96 & 0.79 \\
\hline
\end{tabular}

a Hazard ratio (HR) and $95 \%$ confidence interval (Cl) were adjusted for age (continuous), premature birth (yes, no), birth order (first, second, third, fourth or above), duration of being breast fed in infancy (no, $\leqslant 3,4-8, \geqslant 9$ months), and family history of endometrial cancer (yes, no). b $\mathrm{HR}$ and $95 \% \mathrm{Cl}$ were adjusted for age (continuous), premature birth (yes, no), birth order (first, second, third, fourth or above), duration of being breast fed in infancy (no, $\leqslant 3,4-8, \geqslant 9$ months), and family history of endometrial cancer (yes, no), age at menarche $(\leqslant 10,11,12,13,14,15+$ years), current and past contraceptive use (never, past $<5$ years, past $\geqslant 5$ years, current $<5$ years, current $\geqslant 5$ years), parity $(I, 2,3,4+)$, age at first birth $(\leqslant 24,25-30,30+$ years), age at last birth $(\leqslant 24,25-29,30-34,35-40,>40$ years), physical activity $(<3,3-8,9-17,18-26,27-41,42+$ mets per week), cigarette smoking (never, $1-20,21-40,41+$ pack-years), tamoxifen use (never, past and $<5$ years, past and $\geqslant 5$ years, current and $<5$ years, current and $\geqslant 5$ years), menopausal status (yes, no), age at menopause $(<50,50-52,53+$ years), and postmenopausal hormone use (never, past and $<5$ years, past and $\geqslant 5$ years, current and $<5$ years, current and $\geqslant 5$ years). ${ }^{\circ} \mathrm{HR}$ and $95 \% \mathrm{Cl}$ were adjusted for age (continuous), premature birth (yes, no), birth order (first, second, third, fourth or above), duration of being breast fed in infancy (no, $\leqslant 3,4-8, \geqslant 9$ months), and family history of endometrial cancer (yes, no), age at menarche $(\leqslant 10,11,12,13,14,15+$ years), current and past contraceptive use (never, past $<5$ years, past $\geqslant 5$ years, current $<5$ years, current $\geqslant 5$ years), parity $(1,2,3,4+)$, age at first birth $(\leqslant 24,25-30,30+$ years), age at last birth $(\leqslant 24$, $25-29,30-34,35-40,>40$ years), physical activity $(<3,3-8,9-17,18-26,27-41,42+$ mets per week), cigarette smoking (never, $1-20,21-40,41+$ pack-years), tamoxifen use (never, past and $<5$ years, past and $\geqslant 5$ years, current and $<5$ years, current and $\geqslant 5$ years), menopausal status (yes, no), age at menopause ( $<50,50-52,53+$ years), postmenopausal hormone use (never, past and $<5$ years, past and $\geqslant 5$ years, current and $<5$ years, current and $\geqslant 5$ years), BMI (continuous in $\mathrm{kg} \mathrm{m}^{-2}$ ), BMI at age 18 (continuous in $\mathrm{kg} \mathrm{m}^{-2}$ ), and somatotype at age 5 and age at 10 (ranked from I-9). 
our study from 1976 to 2004 was $88 \%$. Women with higher birthweight were less likely to have been prematurely delivered and to be the first born of their mother, were more likely breastfed, more likely to have ever smoked, and were slightly taller, than women with lower birthweight (Table 1).

Birthweight was not associated with endometrial cancer (HR $(95 \% \mathrm{CI})=1.14(0.83-1.57), 1.10(0.85-1.42), 1.14(0.89,1.46)$ for a birthweight of $<2500,2500-<3182,3182-<3863 \mathrm{~g}$, respectively, as compared to $\geqslant 3863 \mathrm{~g}, P$ for trend $=0.52$ ) in the ageadjusted analysis (Table 2). Results did not differ substantially after adjusting for other potential confounders (covariate-adjusted models I-III) (Table 2). When restricting the analysis to follow-up from 1992 to 2004, the effect estimates did not change substantially from the primary analysis (Table 2). A test for interaction also did not suggest significant heterogeneity with regard to period of follow-up $(1976-1992$ vs 1992-2004) $(P=0.80)$.

The association between birthweight and endometrial cancer did not vary significantly by menopausal status $(P=0.41)$; however, statistical power was limited for premenopausal cases (Table 3). It also did not vary by somatotype at age five, somatotype at age 10, BMI at age 18 , or current BMI (all $\mathrm{P}$ for interaction $\geqslant 0.32$ ).

\section{DISCUSSION}

In two previous prospective cohort studies, both from Sweden, the risk of endometrial cancer has been investigated in relation to birthweight. Based on 112 cases, the incidence of endometrial cancer in women with birthweight of $\geqslant 4000 \mathrm{~g}$ was found to be almost half that of women with birthweight of $<3000 \mathrm{~g}(\mathrm{HR}=0.55$ (95\% CI 0.36-1.17)) (McCormack et al, 2005). Based on 73, no significant association was found between birthweight and endometrial cancer $(\mathrm{HR}=0.65$ (95\% CI $0.34-1.24)$ comparing the incidence in women with birthweight $<2500 \mathrm{~g}$ to that in women $>3000 \mathrm{~g}$ ) (Lof et al, 2007). With more than triple the cases of all previous studies combined, results from the current study do not suggest an association.

Endometrial cancer involves cancerous growth of the endometrium. Unlike breast epithelium, in which terminal differentiation occurs largely during the first full-term pregnancy, the endometrial lining undergoes repeated division and differentiation throughout the reproductive life of a woman. Though birthweight has been related to a higher intrauterine exposure to oestrogen (Petridou et al, 1990) and IGF-I (Yang and Yu, 2000), the relation of birthweight to the profile of endogenous hormone later in life is less clear. In one study, birthweight was not associated with overall premenopausal sex hormone levels, but was inversely associated with luteal estrone and estrone sulphate (Tworoger et al, 2006). Similarly, birthweight was found to be only weakly associated with serum IGF-I levels in adulthood (Schernhammer et al, 2007).

The statistical power of this study would allow us to detect a modest association, if it exists. Many risk factors for endometrial cancer and other early life exposures were assessed and accounted for in the analysis. Though birthweight was queried 16 years after the start of follow-up, when compared with the analysis restricted to prospective follow-up, results including the entire follow-up of 28 years did not differ appreciably. We have previously compared self-reported birthweight with data derived from birth certificates and found self-reported birthweight to be highly reliable $(r=0.74)$ (Troy et al, 1996).

Current research suggests that women can decrease their risk of endometrial cancer mainly through maintaining normal weight, modifying lifestyle, and optimal use of oral contraceptives and postmenopausal hormones (Adami et al, 2002). However, a large number of new cases of endometrial cancer, especially among younger women cannot be accounted for by known risk factors. Clarification of any association between early life exposures and endometrial cancer risk awaits further investigation.

Table 3 Hazard ratio of endometrial cancer by birthweight among 7| 75I participants of the Nurses' Health Study during follow-up from 1976-2004 stratified by menopausal status

HR (95\% Cl)

\begin{tabular}{|c|c|c|c|c|c|c|}
\hline Birthweight (g) & Person-years & No. of cases & Age-adjusted & Covariate -adjusted $I^{\mathrm{a}}$ & Covariate -adjusted $\|^{\mathrm{b}}$ & Covariate-adjusted III \\
\hline \multicolumn{7}{|l|}{ Premenopausal } \\
\hline$\geqslant 3863$ & 72535 & 14 & 1.0 & 1.0 & 1.0 & 1.0 \\
\hline $3182-<3863$ & 280538 & 43 & $0.77(0.41-1.44)$ & $0.79(0.42-1.48)$ & $0.90(0.46-1.78)$ & $0.95(0.47-1.91)$ \\
\hline$<2500$ & 67533 & 8 & $0.59(0.24-1.42)$ & $0.45(0.17-1.19)$ & $0.40(0.14-1.15)$ & $0.43(0.14-1.28)$ \\
\hline$P$ for trend & & & 0.37 & 0.18 & 0.17 & 0.27 \\
\hline \multicolumn{7}{|l|}{ Postmenopausal } \\
\hline $2500-<3182$ & $284 \mid 40$ & 170 & $1.12(0.85-1.48)$ & $1.12(0.85-1.49)$ & $1.10(0.83-1.46)$ & $1.17(0.87-1.56)$ \\
\hline$<2500$ & 102233 & 67 & $1.21(0.86-1.69)$ & $1.21(0.84-1.74)$ & $1.19(0.82-1.72)$ & $1.22(0.84-1.77)$ \\
\hline$P$ for trend & & & 0.46 & 0.48 & 0.58 & 0.38 \\
\hline
\end{tabular}

a Hazard ratio (HR) and 95\% confidence interval (Cl) were adjusted for age (continuous), premature birth (yes, no), birth order (first, second, third, fourth or above), duration of being breast fed in infancy (no, $\leqslant 3,4-8, \geqslant 9$ months), and family history of endometrial cancer (yes, no). ${ }^{\circ} \mathrm{HR}$ and $95 \% \mathrm{Cl}$ were adjusted for age (continuous), premature birth (yes, no), birth order (first, second, third, fourth or above), duration of being breast fed in infancy (no, $\leqslant 3,4-8, \geqslant 9$ months), and family history of endometrial cancer (yes, no), age at menarche ( $\leqslant 10,11,12,13,14,15+$ years), current and past contraceptive use (never, past $<5$ years, past $\geqslant 5$ years, current $<5 y$ ears, current $\geqslant 5$ years), parity $(1,2,3,4+)$, age at first birth $(\leqslant 24,25-30,30+$ years), age at last birth $(\leqslant 24,25-29,30-34,35-40,>40$ years), physical activity $(<3,3-8,9-17,18-26,27-41,42+$ mets per week), cigarette smoking (never, I-20, $21-40,4 I+$ pack-years), tamoxifen use (never, past and $<5$ years, past and $\geqslant 5$ years, current and $<5$ years, current and $\geqslant 5$ years). Age at menopause ( $<50,50-52,53+$ years), and postmenopausal hormone use (never, past and $<5$ years, past and $\geqslant 5$ years, current and $<5$ years, current and $\geqslant 5$ years) were additionally adjusted for in the analysis of postmenopausal endometrial cancer. ${ }^{\mathrm{C}} \mathrm{HR}$ and $95 \% \mathrm{Cl}$ were adjusted for age (continuous), premature birth (yes, no), birth order (first, second, third, fourth or above), duration of being breast fed in infancy (no, $\leqslant 3,4-8$, $\geqslant 9$ months), and family history of endometrial cancer (yes, no), age at menarche ( $\leqslant 10,11,12,13,14,15+$ years), current and past contraceptive use (never, past $<5$ years, past $\geqslant 5$ years, current $<5$ years, current $\geqslant 5$ years), parity $(1,2,3,4+)$, age at first birth ( $\leqslant 24,25-30,30+$ years), age at last birth $(\leqslant 24,25-29,30-34,35-40,>40$ years), physical activity $(<3,3-8,9-17,18-26,27-41,42+$ mets per week), cigarette smoking (never, I-20, $21-40,41+$ pack-years), tamoxifen use (never, past and $<5$ years, past and $\geqslant 5$ years, current and $<5$ years, current and $\geqslant 5$ years), BMI (continuous in $\mathrm{kg} \mathrm{m}^{-2}$ ), BMl at age 18 (continuous in $\mathrm{kg} \mathrm{m}^{-2}$ ), and somatotype at age 5 and age at 10 (ranked from I -9). Age at menopause (<50, 50-52, 53+ years), and postmenopausal hormone use (never, past and $<5$ years, past and $\geqslant 5$ years, current and $<5$ years, current and $\geqslant 5$ years) were additionally adjusted for in the analysis of postmenopausal endometrial cancer. 


\section{ACKNOWLEDGEMENTS}

The Nurses' Health Study is supported by Grant CA87969 from the National Cancer Institute, National Institutes of Health. The current project was funded by Department of Defense Grant W81XWH-05-2-0005.

\section{REFERENCES}

Adami H, Hunter D, Trichopoulos D (2002) Textbook of Cancer Epidemiology. New York: Oxford University Press, pp 359-377

American Cancer Society (2007) Detailed Guide: Endometrial Cancer. American Cancer Society Inc.: Atlanta, GA http://www.cancer.org/ docroot/CRI/CRI_2_3x.asp?dt $=11$,(accessed: 1 May 2007)

Ayabe T, Tsutsumi O, Sakai H, Yoshikawa H, Yano T, Kurimoto $F$, Taketani Y (1997) Increased circulating levels of insulin-like growth factor-I and decreased circulating levels of insulin like growth factor binding protein-1 in postmenopausal women endometrial cancer. Endocrinology 44: 419-424

Breier BH, Vickers MH, Ikenasio BA, Chan KY, Wong WP (2001) Fetal programming of appetite and obesity. Mol Cell Endocrinol 185: 73-79

Ekbom A, Trichopoulos D, Adami HO, Hsieh CC, Lan SJ (1992) Evidence of prenatal influences on breast cancer risk. Lancet 340: 1015-1018

Lof M, Sandin S, Hilakivi-Clarke L, Weiderpass E (2007) Birthweight in relation to endometrial and breast cancer risks in Swedish women. $\mathrm{Br} J$ Cancer 96: $134-136$

McCormack VA, dos Santos Silva I, Koupil I, Leon DA, Lithell HO (2005) Birth characteristics and adult cancer incidence: Swedish cohort of over 11000 men and women. Int I Cancer 115: 611-617

McLaughlin CC, Baptiste MS, Schymura MJ, Nasca PC, Zdeb MS (2006) Birthweight, maternal weight and childhood leukaemia. Br J Cancer 94: $1738-1744$

Michels KB, Xue F (2006) Role of birthweight in the etiology of breast cancer. Int J Cancer 119: 2007-2025

Michos A, Xue F, Michels KB (2007) Birthweight and the risk of testicular cancer: a meta-analysis. Int J Cancer 121: $1123-1131$
The opinions or assertions contained herein are the private views of the authors and are not to be construed as official or as reflecting the views of the Department of the Army or the Department of Defense
Ostlund E, Tally M, Fried G (2002) Transforming growth factor-betal in fetal serum correlates with insulin-like growth factor-I and fetal growth. Obstet Gynecol 100: $567-573$

Petridou E, Panagiotopoulou K, Katsouyanni K, Spanos E, Trichopoulos D (1990) Tobacco smoking, pregnancy estrogens, and birthweight. Epidemiology 1: 247-250

Phillips DI, Fall CH, Cooper C, Norman RJ, Robinson JS, Owens PC (1999) Size at birth and plasma leptin concentrations in adult life. Int J Obes Relat Metab Disords 23: 1025-1029

Sayer AA, Cooper C (2005) Fetal programming of body composition and musculoskeletal development. Early Hum Dev 81: 735 - 744

Schernhammer ES, Tworoger SS, Eliassen AH, Missmer SA, Holly JM, Pollak MN, Hankinson SE (2007) Body shape throughout life and correlations with IGFs and GH. Endocr Relat Cancer 14: $721-732$

Troy LM, Michels KB, Hunter DJ, Spiegelman D, Manson JE, Colditz GA, Stampfer MJ, Willett WC (1996) Self-reported birthweight and history of having been breastfed among younger women: an assessment of validity. Int J Epidemiol 25: $122-127$

Tworoger SS, Eliassen AH, Missmer SA, Baer H, Rich-Edwards J, Michels KB, Barbieri RL, Dowsett M, Hankinson SE (2006) Birthweight and body size throughout life in relation to sex hormones and prolactin concentrations in premenopausal women. Cancer Epidemiol Biomarkers Prev 15: $2494-2501$

Yang SW, Yu JS (2000) Relationship of insulin-like growth factor-I, insulinlike growth factor binding protein-3, insulin, growth hormone in cord blood and maternal factors with birth height and birthweight. Pediatr Int 42: $31-36$ 